\title{
Parenting stress among mothers of adolescents in Sri Lanka: Associated factors
}

\author{
YG Ellawella, P Fonseka, ST Kaththriarachchi
}

\section{Background}

Parenting stress is the tension parents feel in fulfilling their parenting functions. Parenting children of any age is difficult, but it can be especially difficult with regards to older children of pre-teen and teenage years.

Aim

The aim of this study was to describe risk factors for parenting stress among mothers of adolescents aged 15-19 years in the district of Colombo, Sri Lanka.

\section{Methods}

An unmatched case control study was conducted among 421 mothers with high parenting stress, and 421 mothers with low parenting stress. Levels of stress amongst mothers were identified by the administration of the Stress Index for Parents of Adolescents (SIPA), which has been translated and validated for Sri Lanka. An interviewer administered study-specific anonymous questionnaire was used to gather other relevant data.

\section{Results}

Behavioural problems in the adolescent, poor relationship with the adolescent, stressful life events during the mother's adolescence, poor marital satisfaction, and unavailability of support from friends emerged as significant risk factors associated with high parenting stress.

\section{Conclusions}

The risk of high parenting stress among mothers of adolescents was associated with multi-dimensional factors related to the adolescent, mother, family and society. All these factors should be addressed to improve the psychological wellbeing of both the mother and the adolescent.

Key words: Mothers of adolescents, parenting stress, risk factors, SIPA

SL J Psychiatry 2015; 6(2): 15-19

\section{Introduction}

Parenting is the process of promoting and supporting the physical, social and intellectual development of a child from infancy to adulthood (1). The main purpose of parenting is to facilitate optimal development of the child within a safe environment (2). It can be argued that parenting is perhaps the most difficult role that adults play. Society expects parents to create healthy and productive citizens, and whilst most parents fulfill these expectations, there are challenges as well. Therefore, parenting is often a significant source of stress.

Parenting stress, a specific form of stress, has received much attention in scholarly circles in the recent past (35). Abidin described parenting stress as the tension parents feel in fulfilling their parenting functions (4). At a psychological level, parenting stress is defined as an aversive emotional reaction (or "distress") by a parent to the demands of occupying child-care roles. Thus, parenting stress can be seen as resulting from a perceived discrepancy between demands of parenthood and personal resources available to the parent.

Measurement of parenting stress is a complex process and up to recent times, there was no clear consensus among researchers as to how to measure it. However, based on accepted definitions and the age of the child, a number of tools have now been developed by researchers to measure parenting stress. The Stress Index for Parents of Adolescents (SIPA) is a tool that can be used for parents of children aged 11-19 years (6).

The word adolescence is Latin in origin, derived from the verb adolescere, which means "to grow into adulthood”. Adolescence may be defined as the period within the life span when most of a person's biological, cognitive, psychological, and social characteristics change, from what is typically considered child-like to adult-like.

According to the World Health Organization [WHO], adolescence is the period ranging from 10 to 19 years of age (7). It can be further divided in to two stages, namely early and late adolescence. Late adolescence encompasses the latter part of the teenage years, and includes the age range of 15-19 years (8). The adolescent population of Sri Lanka is more than three million in number. Among these adolescents, more than $50 \%$ are in the $15-19$ year age group, comprising $9.7 \%$ of the total population (9).

Adolescents can be a special source of stress to their parents (10). Studies on parenting of children of different 
ages suggest that parents of adolescents often feel the least comfortable and adequate (11). In South Asia, parents often rate their efficacy in child rearing by the degree to which they feel they have provided accurate guidance to the child, in making life decisions (12). In this context, parents are more likely to perceive adolescent autonomy in a negative manner, and thus are more likely to react to their children's behaviors with frustration and increased attempts at control. This ultimately may lead to increased parenting stress $(13,14)$.

According to societal expectations and traditions, women are more often cast in the role of the caregiver than men. Whilst traditions are changing, in Sri Lankan society too, often the mother is the main caregiver of a child of any age.

While fulfilling the caregiver's role, mothers have to face various stressful events. Since mothers are busy looking after everyone else in the family, they often consider their own well-being as being least important. Though both parents can be affected by parenting stress, the reported effect of parenting stress is greater for mothers (15). Studies also suggest that the stress associated with parenting may be qualitatively different from stress associated with other domains, such as workplace stress or financial stress (16).

Conversely, all parents do not find parenting equally stressful. The child, parent, and family factors have proven to be important in understanding parenting stress (4). Characteristics of the child, such as age, temperament, social relationships, developmental disabilities and psychopathologies contribute towards parenting stress $(17,18)$. The risk of stress related to the role of parenting has also been linked to the parental age, educational level, marital status, number of children, income, employment status, and physical and mental health status (19). The marital relationship, relationships between siblings, family atmosphere and the support within the family, as well as factors outside the family, such as socio-economic status and general social support, play a crucial role in predicting parenting stress (20).

There is no published research available on parenting stress in Sri Lanka. Thus, the aim of this study is to describe the stress of mothers who are parenting adolescents in the Sri Lankan context. Identifying the riskfactors for parenting stress would provide professionals, health care workers and education providers critical information regarding parenting stress in Sri Lanka, and thus point towards interventions which may help reduce parenting stress. The findings of this research will ultimately help mothers to fulfill their parenting roles effectively and enjoy their life as parents.

\section{Methods}

We carried out an unmatched case control study in the district of Colombo, in Sri Lanka. It has the highest estimated mid-year population (12.2\%) in Sri Lanka, and of this population, $9 \%$ consist of adolescents aged between 15 and 19 years.

The study population consisted of biological mothers of adolescents aged 15-19 years residing in Colombo. Mothers diagnosed to be having a psychiatric illness and whose adolescents or children of other ages were diagnosed as having severe physical or cognitive impairment were excluded. The required minimum sample was based on $80 \%$ power to detect potential associations between cases and controls at 5\% alpha error, 50\% minimum probability of exposure in the controls; odds ratio (OR) of 2; and 1:1 unmatched case-control ratio.

Though the calculated minimum sample size was 132, all 421 mothers who were identified as having high parenting stress according to the scores of SIPA were included as cases. Four hundred and twenty one mothers who had low parenting stress according to the SIPA, were included as controls.

Data was collected using an interviewer-administered questionnaire (IAQ). A list of potential risk factors associated with parenting stress was identified via a literature review, expert opinion and focus group discussions (FGDs). Based on the conceptual model of parenting stress (4), identified risk factors were grouped under four broad areas: Factors related to the adolescent, the mother, family level factors and other societal factors related to the family. Demographic and socio-economic variables were included in Section 1 of the study instrument. Data collection was done by trained research assistants. The IAQ was administered to all cases and controls.

Ethical clearance for the study was obtained from the Ethics Review Committee of Faculty of Medical Sciences, University of Sri Jayewardenepura, Sri Lanka. All participants who provided informed written consent were included in the study.

Data analysis was carried out using the Statistical Package for Social Sciences (SPSS) version 18. Factors associated with parenting stress were analysed via the Chi-square test and a probability value of $<0.05$ was considered as significant. The OR and its 95\% confidence interval (95\%CI) were also estimated. Risk factors for parenting stress were further explored by logistic regression analysis and adjusting for potential confounding factors. Variables that showed a probability value of $<0.05$ in the bivariate analysis, and other factors considered as important according to the literature were included in the logistic regression analysis. Backward stepwise regression was used.

\section{Results}

The majority of mothers of adolescents among both cases and controls belonged to the 40-44 year age group and were Sinhala and Buddhists. 


\section{Factors associated with high parenting stress}

There was a significant difference in parenting stress across ethnicity and religion. Muslim, Tamil, Burger and Malay mothers were significantly more likely to have high parenting stress compared to Sinhala mothers $\left(\chi^{2}\right.$ $=23.24, \mathrm{df}=1, \mathrm{p}<0.001)$. Likewise mothers who were Christians, Hindu, and Islam were significantly more likely to report high parenting stress compared to mothers who were Buddhists $\left(\chi^{2}=25.20, \mathrm{df}=1, \mathrm{p}<0.001\right)$.

Lower levels of education $\left(\chi^{2}=28.51, \mathrm{df}=1, \mathrm{p}<0.001\right.$ ) lower social class $\left(\chi^{2}=10.41, \mathrm{df}=1, \mathrm{p}=0.001\right)$, low average monthly income $\left(\chi^{2}=14.92, \mathrm{df}=1, \mathrm{p}<0.001\right)$, and employment $\left(\chi^{2}=8.45, \mathrm{df}=1, \mathrm{p}=0.003\right.$ ) were all significantly associated with higher parenting stress.

\section{Factors predicting high parenting stress - findings from logistic regression}

Model Chi-square, measured using Omnibus test was 845.77 and it was statistically significant at $\mathrm{p}<0.001$. A significant Chi-square and non-significant Hosmer and Lameshow test $(p=0.270)$ were proof for the goodness of fit of the model selected for logistic regression. The factors that emerged as significant risk factors for high parenting stress are presented in Table 1 and are described according to four broad areas, namely factors related to adolescent, personal factors of the mother, family level factors and other societal factors related to the family.

Not attending school (OR=2.89, 95\% CI: 1.34-6.24), internalizing behaviours (OR=4.01, 95\% CI: $2.17-7.42$ ), externalizing behaviours (OR=3.92, 95\% CI: 1.03-14.93), frequent internet browsing (OR=4.03, 95\% CI: 1.35-12.08) and need for stylish clothing (OR=5.24, 95\% CI: 2.50-
11.01) among the adolescents were significantly associated with high parenting stress.

Poor relationship with the adolescent $(\mathrm{OR}=4.23,95 \% \mathrm{CI}$ : 1.77-10.09), stressful life events during the adolescence of the mother (OR=3.45, 95\% CI: 1.62-7.35), stressful life events in the past year (OR=3.62, 95\% CI:1.28-10.22), poor perceived health status $(\mathrm{OR}=2.85,95 \% \mathrm{CI}$ : 1.00 8.12) and dissatisfaction regarding the amount of sleep $(\mathrm{OR}=4.26,95 \% \mathrm{CI}: 1.55-11.67)$ were the personal factors regarding the mother that emerged as significant risk factors for parenting stress.

Among family level factors, poor marital satisfaction (OR=6.13, 95\% CI: 1.91-19.69) and low overall support available at home $(\mathrm{OR}=4.34,95 \% \mathrm{CI}$ : 2.38-7.91) were significantly associated with parenting stress.

Lack of moral support from society (OR=2.56, 95\% CI: 1.38-4.73) and unavailability of support from friends (OR=1.82, 95\% CI: 1.01-3.25) were significant societal risk factors.

\section{Discussion}

The relationship between parents and children is an emerging focus for research $(20,21)$. Much research on parenting stress has been done worldwide, but most research is on parents of young children and those with specific problems $(22,23)$. The risk factors associated with parenting stress, especially among mothers of adolescents have not been widely researched. Identification of risk factors of parenting stress is essential to address this emerging issue effectively. Published data on parenting stress in Sri Lanka is not available.

\begin{tabular}{llll}
$\begin{array}{l}\text { Table 1. Risk factors of parenting stress among mothers of adolescents, identified by the logistic regression } \\
\text { model }\end{array}$ & \multicolumn{1}{l}{$\begin{array}{l}\text { Significance } \\
\text { (p-value) }\end{array}$} & $\begin{array}{l}\text { Adjusted } \\
\text { Odd Ratio }\end{array}$ & $\begin{array}{l}95 \% \\
\text { Confidence Interval }\end{array}$ \\
\hline Variable & 0.01 & 2.89 & $1.34-6.24$ \\
& 0.001 & 4.01 & $2.17-7.42$ \\
\hline Not attending school & 0.05 & 3.92 & $1.03-14.93$ \\
Internalising behaviours & 0.01 & 4.03 & $1.35-12.08$ \\
Externalising behaviours & 0.001 & 5.24 & $2.50-11.01$ \\
Frequent internet browsing & 0.00 & 4.23 & $1.77-10.09$ \\
Need for stylish clothing & 0.00 & 3.45 & $1.62-7.35$ \\
Poor relationship with the adolescent & 0.02 & 3.62 & $1.28-10.22$ \\
Stressful life events during adolescence of mother & 0.05 & 2.85 & $1.00-8.12$ \\
Stressful life events in the past year & 0.001 & 4.26 & $1.55-11.67$ \\
Poor perceived health status & 0.001 & 6.13 & $1.91-19.69$ \\
Dissatisfaction about the amount of sleep & 0.001 & 4.34 & $2.38-7.91$ \\
Poor marital satisfaction & 0.04 & 1.82 & $1.01-3.25$ \\
Low overall support available at home & 0.001 & 2.56 & $1.38-4.73$ \\
No support from friends & & & \\
No moral support from society & &
\end{tabular}




\section{Risk factors related to adolescent}

We did not find the age of the adolescent to be a risk factor for high parenting stress in the logistic regression analysis.

Non-schooling among adolescents was associated with high parenting stress in mothers. It is likely that mothers place a high emphasis on the importance of schooling, and they may also feel that the school setting is a more secure environment for their adolescent.

It is hypothesized that the higher parenting stress would be seen in parents of children who had more severe behavioral problems $(24,25)$. A previous cross-sectional study conducted among a 222 mother-child had reported that mothers of children who had behavior problems were more likely to experience maternal caregiver strain and greater disruption in the mother's mental health status (24). Similarly, in our study, having an adolescent with one or more externalizing behaviours was significantly associated with higher parenting stress. High parenting stress in the mother was also associated with excessive internet browsing by adolescents.

\section{Personal factors relevant to the mother}

Parent characteristics are also equally important with regards to experiencing of parenting stress, and this is confirmed by the findings of this study.

The perceived health status of the mother was found to be statistically significant associated with parenting stress. These findings suggest that mothers having good physical and mental health tend to be less stressed and highlight the importance health and positive thinking in reducing parenting stress. However a potential confounder to this hypothesis is that mothers with high parenting stress also can have more physical symptoms due to stress, and they may perceive their health as being poor.

Dissatisfaction about the amount of sleep that the mothers had was identified as a risk factor in the logistic regression analysis. The association between parenting stress and quality of sleep has been supported in the literature to some extent (27).

\section{Family related factors}

For many people, family is their closest environment. Important positive aspects of the family environment include supportive and facilitative interactions, and the absence of conflict.

Factors related to the spouse have a great impact on the mother's perception of stress in the role of parenting. Marital satisfaction, marital discord and physical abuse by the husband were also studied in the present study in relation to the parenting stress. Although bivariate analysis showed significant association of these factors with parenting stress, only poor marital satisfaction remained as a significant risk factor in the multivariate analysis in this study. Our findings also identified low overall support at home as a risk factor. Similar associations between parenting stress and marital life have been reported by several other researchers. In one study based on the 2003 National Survey of Children's Health conducted in the United States, parents reporting high parenting stress had higher odds of violent and heated disagreement than parents reporting less stress (28). Higher parenting stress has been noted among families that report a less cohesive family atmosphere and less involved parenting had higher parenting stress (26).

\section{Other societal factors related to the family}

Factors such as family income, social class, and social support were considered in this study as societal factors related to the family. Proving that well known proverb ' $a$ friend in need is a friend in deed', unavailability of support from friends was identified as a significant risk factor for high parenting stress in the multivariate analysis. Similarly, in a sample of Swedish parents and their children, researchers found a significant relationship between high parenting stress and lack of support (29).

\section{Limitations}

While this study describes factors associated with high parental stress, due to the nature of the study design, the findings do not establish a cause-effect relationship. Therefore we are unable to comment on the etiological value of the above described risk factors, which is a limitation. Thus for example, while lack of support from friends is significantly associated with higher parental stress, it may be secondary to personality factors of mother, which may also be contribute towards poor relationship with spouse/child and high parenting stress.

\section{Conclusions}

The current study elaborates the multi-dimensional nature of parenting stress. Factors related to the adolescent (i.e., externalising and internalising behaviours), personal factors of the mother (i.e., poor perceived health status, stressful life events), family level factors (poor marital satisfaction, lack of support from family) and other factors related to family such as lack of moral support and support from friends emerged as factors significantly associated with parenting stress. The findings of this study suggest that programs to develop parenting skills for parents, as well as family level programs to address issues such as risk behaviours of adolescents and division of household chores, maybe useful in minimizing parental stress.

\section{Acknowledgments}

We acknowledge the financial assistance granted by the National Health Research Council, Ministry of Health, Sri Lanka for conducting this research. 


\section{Declaration of interest}

None declared

PYG Ellawella, Ministry of Health, Colombo, Sri Lanka

P Fonseka, Former Professor of Community Medicine, Faculty of Medical Sciences, University of Sri Jayawardenepura

ST Kaththriarachchi, Department of Psychological Medicine, Faculty of Medical Sciences, University of Sri Jayawardenepura

Corresponding author: YG Ellawela

Email: yamuna.ellawala@gmail.com

DOI http://dx.doi.org/10.4038/sljpsyc.v6i2.8075

\section{References}

1. Davies M, ed. The Blackwell encyclopedia of social work. Oxford: Blackwell; 2000.

2. Reder P, Duncan S, Lucey C. What principles guide parenting assessments? In: Reder P, Duncan S, Lucey C, ed. Studies in the Assessment of Parenting. London: Routledge; 2003.

3. Taber's encyclopedia medical dictionary. $21^{\text {st }}$ ed. Philadelpia: FA Davis; 2009.

4. Abidin RR. Parenting stress index: professional manual. 3rd ed. Odessa, FL: Psychological assessment resources; 1995.

5. Östberg M, Hagekull B. A structural modeling approach to the understanding of parenting stress. J Clin Child Psychol 2000; 29: 615-25.

6. Sheras PL, Abidin RR, Konold TR. Stress Index for Parents of Adolescents. Professional Manual. Odessa, FL: Psychological assessment resources; 1998.

7. World Health Organization. Adolescent development. [homepage on internet] c2015 Available at http:// www.who.int/maternal_child_adolescent/topics/ adolescence/dev/en/. (Accessed March 14, 2015).

8. UNICEF. Adolescence: state of world's children 2011. Available at http://www.unicef.org/adolescence/files/ SOWC_2011_Main_Report_EN_02092011.pdf. (Accessed March 12, 2015).

9. Medical Statistical Unit. Annual Health Statistics Sri Lanka-2006. $2^{\text {nd }}$ ed. Colombo: Ministry of Health 2009.

10. Kidwell J,Fisher JL, Dunham RM, Baranowski M. Parents and adolescents: push and pull of change. In: Figley CR, McCubbin HI, ed. Stress and the family: coping with normative transitions. New York: Bruner/Mazel 1983.

11. Ballenski CB, Cook AS. Mothers' perceptions of their competence in managing selected parenting tasks. Fam Relat 1982; 31: 489-94.

12. Almeida R. Hindu, Christian, and Muslim families. In: McGoldrick M, Giordano J, Pearce JK, ed. Ethnicity and family therapy. New York: Guilford 1996.

13. Carolan MT, Bagherinia G, Juhari R, Himelright J, Mouton-Sanders M. Contemporary Muslim families:
Research and practice. Contemp Fam Ther 2000; 22(1): 67-79.

14. Segal UA. Cultural variables in Asian Indian families. Fam Soc 1991; 72(4): 233- 41.

15. Baker BL, Heller TL. Preschool children with externalizing behaviors: Experience of fathers and mothers. J Abnorm Child Psychol 1996; 24: 513-32.

16. Creasey G, Reese M. Mothers' and fathers' perceptions of parenting hassles: Associations with psychological symptoms, non-parenting hassles, and child behavior problems. J Appl Dev Psychol 1996; 17: 393-406.

17. Baker B, McIntyre L, Blacher J, Cmic K, Edelbrock C,LowC. Pre-school children with and without developmental delay: behaviour problems and parenting stress over time. JIntellect Disabil Res 2003; 47(5): 217-30.

18. Webster-Stratton C. Long-term follow-up of families with young conduct problem children: from preschool to grade school. J Clin Child Psychol 1990; 19(2): 144-9.

19. Jackson A. Maternal self-Efficacy and children's influence on stress and parenting among single black mothers in poverty. J Fam Issues 2000; 21: 3-16.

20. Crnic KA, Low C. Everyday stresses and parenting. In: Bornstein M, ed. Handbook of parenting vol 5 practical issues in parenting. $2^{\text {nd }}$ ed. Mahwah, NJ: Lawrence Erlbaum Associates 2002; 243-67.

21. Deater-Deckard K. Parenting stress and child adjustment: some oldhypotheses and new questions. Clin Psychol Sci Pract 1998; 5: 314-32.

22. Podolski C, Nigg JT.Parent stress andcoping in relation to child with ADHD, severity andassociated child disruptive behavior problems. J Clin Psychol 2001; 30(4): 503-13.

23. Swensen AR, Birnbaum HG, Secnik K, Marynchenko M, Greenberg P, ClaxtonA. ADHD: increased costs for parents and their families. J Am Acad Child Adolesc Psychiatry 2003; 42(12): 1415-23.

24. Sales E, Greeno C, Shear MK, Anderson C. Maternal care giving strain as a mediator in the relationship between child and mother mental health problems. Soc Work Res 2004; 28(4): 211.

25. Dubbs JL. Parent stress reduction through a psychosocial intervention for children diagnosed with attention-deficit/ hyperactivity disorder. [Dissertation] Pennsylvania: Indiana University; 2008.

26. Gallagher S, Phillips AC, Carroll D. Parental stress is associated with poor sleep quality in parents caring for children with developmental disabilities. J Pediatr Psychol 2010; 35(7): 728-37.

27. Moore CG, Probst JC, Tompkins M, Cuffe S, Martin AB. The prevalence of violent disagreements in US families: effects of residence, race/ethnicity, and parental stress. Pediatr 2007; 119(1): 68-76.

28. Anderson LS. Predictors of Parenting Stress in a Diverse Sample of Parents of Early Adolescents in High-Risk Communities. Nurs Res 2008; 57(5): 340-50.

29. Sepa A, Frodi A, Ludvigsson J. Psychosocial correlates of parenting stress, lack of support, and lack of confidence/ security. Scand J Psychol 2004; 45(2): 169-79. 